\title{
Nine key principles to guide Youth Mental Health: Development of Service Models in New South Wales
}

Aims: Historically, the Australian health system has failed to meet the needs of young people with mental health problems and mental illness. In 2006, New South Wales (NSW) Health allocated considerable funds to the reform agenda of Mental Health Services in NSW to address this inadequacy. Children and Young People's Mental Health (CYPMH), a service which provides mental health care for young people 12-24, with moderate to severe mental health problems, was chosen to establish a prototype Youth Mental Health (YMH) Service Model for NSW. This paper describes nine key principles developed by CYPMH to guide the development of YMH Service Models in NSW.

Methods: A literature review, numerous stakeholder consultations and consideration of clinical best practice were utilised to inform the development of the key principles.

Results: Subsequent to their development, the nine key principles were formally endorsed by the Mental Health Program Council to ensure consistency and monitor the progress of YMH Services across NSW. The Mental Health Program Council is the governing body for all public mental health services and programs in NSW. As a result, YMH Services across NSW now have to regularly report on their activities against each of the nine key principles and also demonstrate how each principle is addressed within their service.

Conclusions: The nine key principles provide Mental Health Services a framework for how to reorient services to accommodate $\mathrm{YMH}$ and provide a high quality model of care.

Keywords: adolescence, health knowledge, mental health service, therapy 


\section{Introduction}

The peak period for the onset of mental illness is late adolescence and early adulthood (1-4). Approximately $24.3 \%$ of young Australians aged $12-25$ experience mental health problems and mental illness (5). Many of these mental disorders are chronic if they remain untreated or poorly treated, and significantly impact on a young person's health, wellbeing and quality of life $(3,6)$. Mental illness in young people results in high rates of disability and disruption to schooling, work and family functioning $(7,8)$. However, many young people who require help are reluctant to seek it, and less than $25 \%$ of young people with severe mental health problems receive any professional help $(9,10)$.

Historically, the Australian health system, at both a Federal and State level, failed to meet the needs of young people with mental health problems $(2,11-13)$. Mental health systems followed a traditional model of care (i.e., paediatric versus adult) without consideration of the timeframe for the peak onset of mental illness $(2,12,14)$. Young people aged 18-24 years commonly received services in Adult Mental Health settings, which focused mainly on latestage chronic disorders. Engagement with young people was generally not a function of Adult Mental Health Services, particularly not for those individuals where a mental health disorder was emerging rather than established $(2,15)$. The culture of the adult setting is often insensitive to phases of illness, developmental stages, and to the needs of families and friends (12). In addition, large numbers of young people without a diagnosable disorder, but who presented with sub-threshold symptoms and significant impairment aren't often offered treatment in specialist mental health services (2).

In recent years, the Federal and State Governments have acknowledged that young people fall between the gaps of Child and Adolescent Mental Health and Adult Mental Health Services, and that this results in significant delays in receiving appropriate intervention. To 
redress this gap, the Federal Government responded by establishing the National YMH Foundation called headspace. Headspace aims to deliver improvements in the mental health, social wellbeing and economic participation of young Australians aged 12-25 (16). Headspace sites have been established in each state and territory across Australia. These services provide an entry point for young people to access a broad range of services operating in their local community. In 2007, on the Central Coast in NSW, Australia, Children and Young People's Mental Health (CYPMH) was successful in gaining (on behalf of a local Consortium) one of the first ten National grants to establish headspace (Central Coast) (now called headspace (Gosford)). CYPMH is a community based specialist tertiary service for young people with moderate to severe mental health problems and mental illness. Prior to this (2006), at a State level, the NSW Government responded to this service gap by committing to a reform agenda to reconfigure and integrate mental health care for young people. Funds (\$28.6 Million) were allocated across the State to support the reorientation of Mental Health Services and enhance their capacity to work with young people who require specialist mental health support. Because of its long history of successfully reconfiguring local mental health service delivery for young people, CYPMH was chosen to develop and evaluate a prototype YMH Service Model. A combination of these two funding streams contributed to the development of ycentral, which is a site that subsumes CYPMH and headspace (Gosford). ycentral was developed to provide an integrated service model incorporating primary, secondary and tertiary mental health care for young people at one accessible site.

The first step in establishing a prototype YMH Service Model involved developing a set of key principles that represent the necessary components of a YMH Model. The aim of the current paper is to describe these principles, and how they were identified and implemented within CYPMH. 


\section{Methods}

In early 2007, a literature review was conducted focusing on the main components necessary to the development of a YMH Model. A range of databases including Medline, PsychLit, CINAHL, Evidence-based Practice (including Cochrane Library), and PubMed were searched. In addition, discussions with leading academics in the field ensured that access to the latest up to date unpublished research was included. Feedback from young people and carers, and relevant stakeholders such as Adult Mental Health, Youth Health and Drug and Alcohol Services, was also sought. Information from this literature review and stakeholder feedback informed the key principles. A full discussion of this literature is available on request from the authors (17).

Concurrently YMH Services in rural and remote areas of NSW were also considering YMH principles that could meet their specific needs. In 2007 both sets of key principles were discussed at a NSW YMH Forum. Commonalities between the principles were identified, and in June 2008 nine key principles for YMH Services were endorsed by the NSW Mental Health Program Council. The NSW Mental Health Program Council embedded the key principles within a reporting pro-forma, and NSW YMH Services are now required to report their activities annually against each principle and demonstrate how each principle is addressed within their Service.

Whilst some of these principles may be common to other mental health populations, at the time of their development there was a dearth of information regarding the development and implementation of youth mental health services. The development to the principles was an attempt to provide guidance for this. 


\section{Results: The nine key principles}

\section{Principle 1: Commitment to a Promotion and Prevention Framework for Mental Health}

'Mental health promotion' refers to actions or behaviours that maximise the wellbeing and mental health of individuals and populations (18). Mental health promotion can increase the level of mental health literacy, reduce the stigma of mental illness and improve the attitude toward seeking help all of which have been associated with increasing young people's helpseeking behaviour (19). 'Mental health prevention' refers to interventions designed for individuals displaying early signs and symptoms of a mental health disorder before the initial onset of the disorder $(20,21)$. There is accumulating evidence that supports the effectiveness and value of early intervention in $\mathrm{YMH}(22-27)$.

YMH services require an underlying framework of mental health promotion and prevention to provide structures and supports to assist young people to live safe, productive and fulfilling lives. Within CYPMH there is an expectation that clinicians maintain a commitment to promotion, prevention and early intervention. This ensures clinicians interface with school settings, and work with the community to engender an understanding that mental illnesses are treatable, and to encourage early entry to care to improve outcomes and lessen stigma and discrimination related to mental illness.

\section{Principle 2: Improving Early Access}

Improving access is important to ensure young people with mental health problems and mental illness receive intervention in the early stages of the illness. An early intervention paradigm is grounded on the notion that the early stages of illness are more responsive to treatment, can be treated with simpler and less invasive methods, have a better prognosis and may prevent the progression of mental illness into chronic and treatment resistant states (7). Numerous barriers prevent young people from receiving early access to mental health 
care which significantly affect clinical and functional outcomes $(28,29)$. Identified 'structural barriers' that impact on young people's help seeking behaviour include support systems (i.e., family, school or community), referral pathways, health system structures and cost (i.e., payment systems), all of which should be considered when developing YMH Service Models (30). For instance, changing health care structures by integrating $\mathrm{YMH}$ with other services provides more holistic care for young people, and a 'soft access' point to mental health.

This principle informed the development of 'ycentral' as a collocated 'one stop youth mental health shop'. CYPMH and headspace (Gosford) are both permanently collocated at ycentral, whilst other services including Private Allied Health Providers, drug and alcohol, child protection, young carer support, vocational services and General Practitioners (Family Doctors) are provided on a sessional basis. All services are provided at no cost to the young people. A number of services are subsidized by the Australian Government through the Medical Benefits Scheme. This high level of service integration allows young people to access three levels of mental health care at one site. Primary health care is provided through onsite GPs and targets young people with either no mental health problems or mild mental health problems. Secondary mental health care (for young people with mild to moderate mental health problems) is provided through Private Allied Health staff at headspace. Tertiary mental health care is provided by CYPMH, who focus on young people with moderate to severe mental health problems and mental illness. To ensure a smooth client journey through ycentral a centralised intake and assessment point was established to allow young people to enter and exit the system in a coordinated way. One file was created for each client to ensure that an effective flow of information occurs. To ensure ycentral was youth friendly indicators for a youth appropriate service were considered (31) and numerous consultations with young people were held.

Another way to improve early access for young people is linking YMH services with a webbased service. Recent research highlights that a growing proportion of young people seek 
support and advice from the Internet $(30,32,33)$, including marginalised young people (34). At CYPMH, this informed an 'e' YMH initiative and an 'e' youth mental health coordinator was employed. The ycentral web based service (www.ycentral.com.au) was established to reach young people who may not be able to, or simply do not want to, access services in person. The ycentral website contains information about youth related issues and local services. It also offers an email support service, where young people can seek help regarding their mental health or other health issues. Young people were pivotal in the development of a youth friendly ycentral website.

\section{Principle 3: Sustainable Clinical Governance of Youth Mental Health and Quality Control}

YMH clinical governance should address systemic issues in relation to fragmentation of services and ensure care for young people is safe, timely and appropriate. Clinical governance is "the set of processes and systems which ensure the safety and highest quality of the processes of care" (35). The concept of clinical governance integrates clinical decision-making in a management and organisational framework. It requires clinicians and administrators to take joint responsibility for the quality of clinical care delivered by the organisation $(36,37)$. One of the key challenges for clinical governance mechanisms within services attempting to establish YMH Service Models is bridging the differing cultures of paediatric, adolescent, and adult health care.

Further, there is a need for sustained research and evaluation to determine how best to reorient the mental health service system to meet the needs of young people with a mental disorder. YMH Service Models are more likely to succeed if evaluation and data collection is an integral part of model development and review.

To address this principle at CYPMH a number of strategies were implemented. An evaluation plan was developed to report on all aspects of the model, including number of 
young people accessing the service, client satisfaction with the service, improvement in clinical outcomes, number of staff recruited and staff satisfaction at all stages. Additionally, there was a heightened focus on data collection. Data compliance was included in new job descriptions and became an expectation and priority of the service. All new staff were trained in data collection as part of their orientation to the service and data compliance was integrated in performance reviews. To date the clinical model has undergone a number of revisions each of which have been informed by available evidence including collected referral data, quality improvement projects, and client and staff satisfaction.

\section{Principle 4: Promoting ‘Best Practice’ Youth Mental Health Clinical Services}

YMH Services need to provide interventions based on the best available evidence. Clinical services need to focus on a broad range of mental disorders including substance abuse and dependence. The assessment should not only focus on psychiatric symptoms but also include areas such as family, vocational, educational and social functioning (38). Given the diversity of mental health issues, disorders and comorbidities experienced by young people, it is difficult to recommend one specific model of care. While there is limited research on specific intervention models for young people with severe mental disorders, there is growing evidence that case management is an effective intervention for this population $(39,40)$. Based on the experience of clinicians within $\mathrm{CYPMH}$, incorporating several aspects of various case management models (such as Intensive Case Management, Assertive Case Management and Clinical Case Management) may be necessary to best meet the needs of the young person. A low consumer to staff ratio and assertive outreach component is also essential. At CYPMH, clinicians have a caseload of 15-20 clients and are focused on engaging the young person. They provide assertive follow up, remain flexible and creative in their approach, and provide interventions that are focused on hope and recovery.

As previously mentioned the clinical model at CYPMH has undergone several revisions in order to provide the best possible service to young people. This has included changes to 
access and triage, entry criteria, changes from specialist positions (eg Drug and Alcohol Worker and YMH Family Worker) to generalist YMH positions, a greater focus on intensive case management and a reduced emphasis on a group program approach. These changes have been informed by ongoing service evaluation, including the collection of client data and feedback from clients, carers and clinicians.

\section{Principle 5: Developing Effective Strategic Partnerships}

Strong partnerships between public, private, generalists and specialist services are fundamental for the success of YMH Service models. Partnership enables services to increase their capacity to respond appropriately and become more closely aligned with clients' needs. Willingness to work towards a shared goal, a strong level of mutual trust and commitment at the executive level, and joint responsibility for directions and activities related to the partnership are vital to successful partnerships $(41,42)$. A wide range of government and non-government agencies could be approached to develop partnerships to support YMH Service Models. For instance, there is a need for a stronger partnership between Mental Health Services and Drug and Alcohol Services. Historically, there has been a lack of integration between these services in Australia, and this has contributed to poor detection and treatment of mental illness amongst young people with substance use issues. This results in a waste of resources and long-term psychiatric and substance use problems which could have been prevented. Partnerships with other services young people frequently access such as education, vocational and employment services should be a high priority.

To drive the development of Youth Mental Health Services on the Central Coast, CYPMH consolidated partnerships with the local Youth Health Service, Adult Health Service, Drug and Alcohol Service, Division of General Practice and a Community Housing Provider. These organisations all had extensive experience in providing services to young people and were committed to a shared goal of improving mental health care for young people on the Central Coast. The development of appropriate partnerships was informed by the results of a 
partnership survey which was completed by prospective partners. This survey asked prospective partners about their practices in working with young people, including referral processes and criteria, how young people were triaged and where they were referred onto. This allowed for the identification of service gaps across the region and the development of partnerships to address these.

Additionally, the Central Coast Youth Mental Health Consultative Committee was established to involve broader representation for a range of Government and NonGovernment Organisations. This group met quarterly to provide input into the development of ycentral and headspace Gosford service development. Several working parties were also established that included representatives from relevant stakeholders. Information on the progress of initiatives was regularly communicated to organisations working with young people, through the monthly Central Coast Youth Interagency meeting.

\section{Principle 6: Focus on Recovery and Hope}

The development of YMH Service models should be driven by a focus on recovery and hope. Recovery relates to being able to live well in the presence or absence of a mental health problem or mental illness. It has a focus on achieving wellness, not just on treating the illness (43), and can be characterised by maximising well-being, empowerment, the redefinition of the self, the emergence of hope and optimism and overcoming symptoms (44). A focus away from merely treating illness towards achieving wellness was identified as a key priority in the National Mental Health Plan (45). Recovery oriented services need to offer treatment and care in an atmosphere of hope and optimism $(45,46)$. Specialised recovery programs that promote hope, wellbeing and autonomy are of great benefit to both young people with first episode of illness and those with more chronic forms of illness (11, 45). Particularly, there is a need to integrate educational and vocational assistance with mental health care in order to restore hope among young people of ever realising their vocational goals and feeling included as valued members of society $(47,48)$. To address this 
principle within CYPMH a Vocational Education, Training and Employment worker and an arts based recovery worker were employed to support young people in their recovery journey. Additionally, to further facilitate young people's recovery, Centrelink was collocated at ycentral on a sessional basis, as was GITS (Getting it Together Scheme) provided by an NGO.

\section{Principle 7: Establishing youth participation in governance, planning \& implementation}

Consumer participation in service planning, delivery and evaluation is a fundamental factor in the success of health services (49-51). From a service perspective, the involvement of young people ensures that services are youth friendly, that barriers to care are reduced, and that the consumers' needs are better met $(52,53)$. Meaningful youth participation enhances young peoples' sense of connectedness, belonging and value, and this in turn improves mental health and wellbeing $(54,55)$. Young people's views should be the starting point of any Service Development.

In partnership with headspace Gosford, CYPMH established a youth participation model, and employed 16 young people aged 15-24, on a casual basis to be involved in the ongoing development and implementation of the NSW YMH Service Model. These young people were involved in 63 community consultations and attended 35 community events. They were instrumental in ensuring ycentral developed as a youth friendly site. They were involved in both the design and fit out of the site, numerous working parties guiding the development of services at ycentral and informing the development of the ycentral website.

\section{Principle 8: Improving Participation of Families and Carers in Mental Health Services}

Australian Government policy recognises carer and family involvement as a high priority in all aspects of the development, planning, implementation and evaluation of Mental Health Services (56). A carer is defined as a family member, friend, neighbour or other community 
member whose life is affected by virtue of his or her close relationship with a consumer, or who has a chosen caring role with a consumer (57). Involving families and carers in service development and the treatment of young people is recommended for a number of reasons. It improves family functioning, carer wellbeing, and client compliance to treatment; and reduces the burden of care and the incidence of relapse (58-60). YMH Service Models should acknowledge and engage families and carers in all levels of service development. To this effect, CYPMH developed a carer strategy focussed on empowering families to be actively involved in the young person's care. Initiatives within this strategy included training clinicians in working with carers and families, the development of a carers' library, facilitating a number of carers' forums, involving carers in service feedback and the development of the 'minds, myths and me' booklet for young carers. This booklet is a fact pack for young people who live with someone with a mental illness (61).

\section{Principle 9: Developing a Youth Mental Health Workforce}

The provision of quality mental health care is dependent upon workforce attitudes, skills, training and education (62). Mental Health staff require the skills and knowledge to provide evidence-based interventions across the spectrum of prevention, early intervention and clinical management, regardless of their professional background (63). Identification of the training and education needs of the $\mathrm{YMH}$ workforce is essential, as is the provision of appropriate training to meet these identified needs. Additionally, the provision of clinical supervision, mentoring and evidence-based training is important to up skill and retain staff. YMH Service Models should implement appropriate workforce development initiatives to meet these needs. CYPMH provides clinicians with access to numerous workforce development opportunities including internal monthly training and education sessions and regular

supervision.

Additionally, in collaboration with headspace Gosford a training and education strategy was implemented across the Central Coast Sector. This initiative included the employment of a 
Training and Education Project Officer and the development of training material specific to best practice in youth mental health. YMH workshops and seminars were developed and delivered, specifically targeting workers within the $\mathrm{YMH}$ sector across three tiers including specialist YMH workers, vocational workers and 'point of first contact' workers (eg school staff and youth workers). Between 2007-2009 a total of 383 practitioners participated in this training, in 65 formal training interventions (64).

\section{Discussion and Conclusion}

The establishment of a prototype YMH Service Model was challenging, multifaceted and entailed substantial service reform. It required the development of strategic partnerships with various government and non-government organisations. It also required the reconfiguration of the CYPMH clinical service model to provide services for young people aged 12-24 years with moderate to severe mental health problems and mental illness, which was a significant change in service delivery. Prior to this service reform young people aged 18-24 years old were cared for within the Adult Mental Health system.

To date, CYPMH's clinical service model has been reconfigured three times in order to meet the increasing service demand and reflect best practice. To ensure staff understood and supported the initiatives, these changes were strongly informed by staff. Staff were consulted throughout the development process and given the opportunity to provide anonymous feedback on various aspects of the model through surveys. Staff participation is one of the most important, but often overlooked, factors for successful organisational change (65).

The present paper provides an overview of each of the nine key principles developed by CYPMH to guide the establishment of YMH Service Models, and some of the ways in which 
these principles have been implemented at CYPMH. Whilst each principle must be addressed, flexibility in their implementation is essential to allow variation in models to match the needs and resources of individual services. The key principles provide a framework for services that aim to reconfigure their mental health service to include a YMH model of care, not only in NSW but across Australia. YMH services that are guided by these principles have the potential to be successful in engaging young people and their families and providing an appropriate, safe and high quality model of care. The nine key principles initially developed by CYPMH continue to be consistent with best practice principles recommended by key bodies such as the International Declaration of Youth Mental Health and with more recent literature highlighting the need for youth mental health services to be 'interdisciplinary, collaborative, accessible and youth friendly' (66). 


\section{References}

1. Kessler RC, Chiu W, Demler O, Walters E. Prevelance, severity, and comorbidity of 12-month DSM IV disorders in the National comorbidity survey replication. Archives of General Psychiatry. 2005;62:617-27.

2. McGorry P, Bates T, Birchwood M. Designing youth mental health services for the 21st century: examples from Australia, Ireland and the UK. The British Journal of Psychiatry. 2013 January 1, 2013;202(s54):s30-s5.

3. Kessler RC, Avenevoli S, Costello JE, Georgiades K, Green JG, Gruber MJ, et al. Prevalence, Persistence, and Sociodemographic Correlates of DSM-IV Disorders in the National Comorbidity Survey Replication Adolescent Supplement. 2012;69(4):372-80.

4. Orygen Youth Health Research Centre. The Australian Health Workforce Institute: Addressing Workforce Challenges for Youth Mental Health Reform. Australian Health Workforce Institute and The University of Melbourne, 2013.

5. Access Economics. The Economic Impact of Youth Mental Illness and the CostEffectiveness of Early Intervention. Report by Access Economics Pty Limited, 2009.

6. Gibbs SJ, Fergusson DM, Horwood LJ. Burden of psychiatric disorder in young adulthood and life outcome at age 30. British Journal of Psychiatry. 2010;197:122-7.

7. McGorry P. Reforming youth mental health. Australian Family Physician. 2006;35(5):314.

8. McLoone J, Hudson JL, Rapee R. Treating anxiety disorders in a school setting. Education \& Treatment of Children. 2006;29:219-42.

9. Australian Bureau of Statistics. National survey of mental health and well-being. Summary of results Cat No 4364.0. Canberra: Australian Bureau of Statistics, 2008.

10. Patulny R, Muir K, Powell A, Flaxman S, Oprea I. Are we reaching them yet? Service access patterns among attendees at the headspace youth mental health initiative Child and Adolescent Mental Health. 2013;18(2):95-102.

11. Hickie I, Groom G, McGorry P. Australian mental health reform: Time for real outcomes. Medical Journal of Australia. 2005;182:401-6.

12. McGorry P. The specialist youth mental health model: Strengthening the weakest link in the public mental health system. Medical Journal of Australia. 2007;187:53-6.

13. McGorry P, Purcell R, Hickie I, Jorm A. Investing in youth mental health is a best buy. Medical Journal of Australia. 2007;187(7):5-7.

14. Coughlan H, Cannon M, Shiers D, Power P, Barry C, Bates T, et al. Towards a new paradigm of care: the International Declaration on Youth Mental Health. Early Intervention in Psychiatry. 2013;7(2):103-8. 
15. Zubrick S, Silburn S, Burton P, Blair E. Mental health disorders in children and young people: Scope, cause and prevention. Australian and New Zealand Journal of Psychiatry. 2000;34(4):570-8.

16. McGorry PD, Tanti C, Stokes R, Hickie I, Carnell K, Littlefield LK, et al. headspace: Australia's National Youth Mental Health Foundation- where young minds come first. Medical Journal of Australia. 2007;187(7):S68-70.

17. Northern Sydney Central Coast Mental Health. A Youth Mental Health Model on the Central Coast: Youth Mental Health Literature Review. Gosford: Northern Sydney Central Coast Area Health Service, CYPMH, 2007.

18. Sturgeon S. Promoting mental health as an essential aspect of health promotion. Health promotion international. 2006;21(1):36-41.

19. Rickwood D, Deane F, Wilson C, Ciarrochi J. Young people's help-seeking for mental health problems. Australian e-Journal for the Advancement of Mental Health. 2005;4(3).

20. WHO. Promoting mental health: concepts, emerging evidence, practice: summary report. Geneva: World Health Organization, 2004.

21. Herrman H, Saxena S, Moodie R. Promoting mental health: concepts, emerging evidence, practice. Geneva: World Health Organization, 2004.

22. Singh SP, Fisher H, L. Early intervention in psychosis: obstacles and opportunities. Advances in Psychiatric Treatment. 2005;11:71-8.

23. Bertelsen M, Jeppesen $P$, Petersen L. Suicidal behaviour and mortality in 547 firstepisode psychotic patients: the OPUS trial. British Journal of Psychiatry. 2007;191:140-6.

24. Power $P$, Robinson J. Suicide prevention in first-episode psychosis. In: McGorry P, Jackson $\mathrm{H}$, editors. The recognition and management of early psychosis: a preventative approach. 2nd ed. Cambridge: Cambridge University Press; 2009.

25. McCrone $\mathrm{P}$, Craig $\mathrm{T}$, Power $\mathrm{P}$, Garety $\mathrm{P}$. Cost-effectiveness of an early intervention service for people with psychosis. British Journal of Psychiatry. 2010;196(5):377-82.

26. McGorry P. Early Intervention in Psychiatry: The Next Developmental Stage. Early Intervention in Psychiatry. 2012;6(1):1-2. PubMed PMID: 70599556.

27. Merry SN, Hetrick SE, Cox GR, Brudevold-Iversen T, Bir JJ, McDowell H. Psychological and education interventions for preventing depression in chiildren and adolescents Cochrane Database of Syst Reviews 2011;7(12).

28. McGorry P, Purcell R, Goldstone S, Amminger G. Age of onset and timing of treatment for mental and substance use disorders: implications for preventive intervention strategies and models of care. Current Opinion in Psychiatry. 2011;24(4):301-6.

29. Reavley N, Cvetkovski S, Jorm A, Lubman D. Help-seeking for substance use, anxiety and affective disorders among young people: results from the 2007 Australian 
National Survey of Mental Health and Wellbeing. Australian and New Zealand Journal of Psychiatry. 2010;44(8):729-35.

30. Rickwood D, Deane FP, Wilson C. When and how do young people seek professional help for mental health problems? Medical Journal of Australia. 2007;187:S35S9.

31. Health NCftAoA. ACCESS Study: Youth Health - Better Practice Framework. Westmead: The Children's Hospital at Westmead, 2005.

32. Nicholas J, Oliver K, Lee K, O'Brien M. Help-seeking behaviour and the Internet: An investigation among Australian adolescents. Advances in Mental Health. 2004;3(1):16-23.

33. Álvarez-Jiménez M, Gleeson J, Bendall S, Lederman R, Wadley G, Killackey $\mathrm{E}$, McGorry PD. Internet-based interventions for psychosis: a sneak-peek into the future. Psychiatric Clinics of North America. 2012;35(3):735-47.

34. Blanchard M, Metcalf A, Degney J, Hermann H, Burns J. Rethinking the digital divide: Findings from a study of marginalised young people's information communication technology (ICT) use. Youth Studies Australia. 2008;27(4):35-42.

35. O'Connor N, Paton M. 'Governance of' and 'Governance by': implementing a clinical governance framework in an area mental health service. Australasian Psychiatry 2008;16(2):69-73.

36. Donaldson L, Gray J. Clinical governance: A quality duty for health care organisations. Quality in Health Care. 1998;7:37-44.

37. NSW Department of Health. NSW Clinical Governance Directions Statement: NSW Patient Safety and Clinical Quality Program. Sydney: NSW Department of Health, 2005.

38. Stoep A, Weiss N, McKnight B, Beresford S, Cohen P. Which measure of adolescent psychiatric disorder - diagnosis, number of symptoms, or adaptive functioning - best predicts adverse young adult outcomes? . Journal of Epistemology and Community Health. 2002;56:56-65.

39. Jorgensen P, Nordentoft M, Abel M, Gouliaev G, Jeppesen P, Kassow P. Early detection and assertive community treatment of young psychotics: The OPUS Study. Rationale and design of the trial. Social psychiatry and psychiatric epidemiology. 2000;35(7):283-7.

40. Craig T, Garety P, Power P, Rahaman N, Colbert S, Fornells-Ambrojo M. The Lambeth Early Onset (LEO) team: Randomised controlled trial of the effectiveness of specialised care for early psychosis. British Medical Journal. 2004;329:1067-72.

41. Wall D, Boggust M. Developing managed clinical networks. Clinical Governance Bulletin. 2003;3:2-4. 
42. Mattessich P, Murray-Close M, Monsey B. Collaboration: What Makes It Work: A Review of Research Literature on Factors Influencing Successful Collaboration 2nd ed. Saint Paul, Minnesota: Amhert H Wilder Foundation; 2001.

43. Lloyd C, Tse S, Deane FP. Community participation and social inclusion: How practitioners can make a difference. Australian e-Journal for the Advancement of Mental Health. 2006;5(3).

44. Rickwood D. Pathways of recovery: Preventing relapse. Canberra: Department of Health and Ageing, 2004.

45. Commonwealth of Australia. Fourth National Mental Health Plan: An agenda for collaborative government action in mental health 2009-2014. Canberra: Commonwealth of Australia, 2009.

46. Lester H, Gask L. Delivering medical care for patients with serious mental illness or promoting a collaborative model of recovery? British Journal of Psychiatry. 2006;188:401-2. 47. Lloyd C, Waghorn G. The importance of vocation in recovery for young people with psychiatric disabilities. British Journal of Occupational Therapy. 2007;70(2):50-9.

48. Rinaldi M, Killackey E, Smith J, Shepherd G, Singh SP, Craig T. First episode psychosis and employment: a review. International Review of Psychiatry. 2010;22(2):148-62. 49. Lloyd C, King R. Consumer and carer participation in mental health services. Australasian Psychiatry. 2003;11(2):180-4.

50. Happell B, Roper C. The role of a mental health consumer in the education of postgraduate psychiatric nursing students: the students' evaluation. Journal of Psychiatric and Mental Health Nursing. 2003;10(3):343.

51. Swanton R, Collin P, Burns J, Sorensen I. Engaging, understanding and including young people in the provision of mental health services. International journal of adolescent medicine and health. 2007;19(3):325-32.

52. James AM. Principles of youth participation in mental health services. Medical Journal of Australia. 2007;187(7):57-60.

53. Sozomenou A, Mitchell P, Fitzgerald M, Malak A, Silove D. Mental Health Consumer Participation in a Culturally Diverse Society. 2000.

54. Oliver KG, Collin P, Burns J, Nicholas J. Building Resilience in Young People through Meaningful Participation. Australian e-Journal for the Advancement of Mental Health. 2006;13(1):1-7.

55. Revans L. The participation of young people in developing social care. Community Care. 2009;28:24-6.

56. McMahon J, Hardy J, Carson R. Identifying the carer project: Final report and recommendations for the Commonwealth Department of Health and Ageing Australia: Private Mental Health Consumer Carer Network undated. 
57. Beyond Blue and Mental Health Council of Australia. Mental Health Discrimination \& Insurance: A survey of consumer experiences Canberra: MHCA, 2011.

58. Birchwood M. Pathways to emotional dysfunction in the first episode psychosis. British Journal of Psychiatry. 2003;182:373-5.

59. Ohaer J. The burden of caregiving in families with a mental illness: A review of 2002. Current Opinion in Psychiatry. 2002;16:457-65.

60. Cleary M, Freeman A, Walter G. Carer participation in mental health service delivery. International Journal of Mental Health Nursing. 2006;15(3):189-94.

61. Minds, myths and me: fact pack for young people who live with someone with a mental illness Available from: http://www.ycentral.com.au/yworker/resources/mind\%20myths\%20and\%20me-

Central\%20Coast-1.pdf.

62. Council of Australian Governments. National Action Plan on Mental Health 2006 2011. Canberra: COAG, 2006.

63. Conway M, McMillan M, Becker J. Implementing workforce development in health care: A conceptual framework to guide and evaluate health service reform. Human Resource Development Journal. 2006;8(1):129-39.

64. Howe D, B B-A, Bochynska K, S B, Ch E, S C, et al. headspace Central Coast Training and Education Project Report. Gosford: headspace Central Coast, 2010.

65. Bolman LG, Deal TE. Reframing Organisations: Artistry, Choice, and Leadership. San Francisco: Josey-Bass; 2008.

66. Hickie I. Youth mental health: we know where we are and we can now say where we need to go next. Early Intervention in Psychiatry. 2011;5(Suppl 1):63-96. 